Resenha Entomológica / Entomological Report

\title{
WHY ARE THE SUBFAMILY RELATIONSHIPS OF TRIATOMINAE (HEMIPTERA: REDUVIIDAE) IMPORTANT?
}

\section{Carl W. Schaefer}

\section{Resumo}

Por que as relações da subfamília Triatominae (Hemiptera: Reduviidae) são importantes? - Esta pergunta se divide em duas: Triatominae é uma subfamília monofilética ? e, se for, a que outras subfamílias de Reduviidae estaria relacionada? Se a resposta para a primeira pergunta for sim, então o que se sabe para alguns membros da subfamília Triatominae pode ser verdade para outros membros; se a resposta for não, então nenhuma predição pode ser feita. Como muitos membros da subfamília Triatominae têm importância médica, tais predições são vitalmente (literalmente) importantes. Pela mesma razão, o conhecimento de subfamílias relacionadas a triatomíneos de importância medica é importante: aqui também predições sobre um membro relacionado podem estar baseadas no conhecimento de outros. Estes pontos são discutidos aqui, e a evidência a favor e contra (especialmente contra) a monofilia de Triatominae é discutida. O status de Linshcosteus, o único gênero de Triatominae do Velho Mundo, também é discutido.

Palavras-chaves: Harpactorinae, Linshcosteus, Phylogeny, Peiratinae, Reduviinae.

Department of Ecology and Evolutionary Biology, University of Connecticut, Storrs CT 06269-3043 U.S.A. E-mail: schaefer@uconnvm.uconn.edu

Recebido em: 04/01/2005.

Aceito em: 31/01/2005. 


\section{Abstract}

Why are the subfamily relationships of Triatominae (Hemiptera: Reduviidae) important?-This question is really two: Is Triatominae a phylogenetically valid monophyletic subfamily; and, if it is, to what other reduviid subfamilies is it most closely related? If the answer to the first question is Yes, then what one knows about one member of Triatominae may be true for other members; if the answer is No, then no such prediction can be made. Because many members of Triatominae are of medical importance, such predictions are vitally (literally) important. For the same reason, knowledge of the subfamily relatives of medically important triatomines is important: For here too predictions about one related member can be based on knowledge of others. These points are discussed here, and the evidence for and against (especially against) monophyly of Triatominae is also discussed. The status of Linshcosteus, the only Old World genus of Triatominae, is also discussed.

Key words: Harpactocorinae, Linshcosteus, Phylogeny, Peiratinae, Reduviinae.

The problem of the systematic/phylogenetic relationships of the reduviid subfamily Triatominae consists really of two questions. First: Is Triatominae actually a true independent subfamily at all? Or, does it, or do some genera in it, belong to one or more other reduviid subfamilies? Second: If indeed Triatominae is a separate subfamily, defined (as it would have to be) by advanced character states found in it alone, then to what other reduviid subfamilies is Triatominae closely related?

Unfortunately, we still do not know enough to answer these questions satisfactorily (Schaefer, 2003). And so, here I shall show why answering these questions is important, for several reasons.

Triatominae is unusual in the Reduviidae because all of its members feed on vertebrate blood. Very few other members of the suborder Hemiptera: Heteroptera do so: Cimicidae (bed bugs) and Polyctenidae feed on blood; some (all?) members of the tribe Cleradini (Rhyparochromidae: Rhyparochrominae; classification of Henry, 1997) do so. But other records of such feeding are scattered and reflect accidental adventitious feeding (Schaefer, 2000; 2004). 
There are about 140 species in the Triatominae (Galvão et al., 2003; Carcavallo et al., 2000), and all of them feed on vertebrate blood. Because this habit is unusual in the Hemiptera, it is generally thought to be an advanced characteristic, unique to the subfamily, and partial evidence that the subfamily arose only once-that is, from a single common ancestor which adopted the vertebrate-blood feeding habit. I shall return to this idea, and show how it can be turned around.

The importance of the Triatominae lies in the fact that some of its members feed on humans. The habits and preferred habitats of these triatomines cause them to come into contact with humans; moreover, humans live in groups, and therefore provide a convenient and plentiful source of food for insects already preadapted to feeding on vertebrate blood.

These bugs are important, however, for a more important reason. Blood feeding is annoying but, usually, not hazardous. Unfortunately, many of these human-feeding bugs transmit Trypanosoma cruzi, the protozoan that causes Chagas disease. The human and economic cost of this disease in the American tropics and subtropics is sadly large (Schofield, 1994; Schaefer, 1995).

No-one questions that these bugs are of great importance to humans. But why does this realization make it important to know what are the evolutionary relatives of Triatominae? Certainly there is scientific interest in learning these evolutionary (phylogenetic) relationships; but are there practical benefits as well? In short, can learning about the evolutionary relationships of Triatominae help us to control those triatomines that transmit T. cruzi? I believe (and hope to show here) that the answer is Yes.

I believe the answer is yes because of systematics. Systematics is the ordering of organisms - that is, the logical grouping of organisms according to their evolutionary relationships. Closely related organisms are grouped closely together (that is, taxonomically); and distantly related organisms are grouped farther apart. As a result, if one knows the group to which an organism belongs, one knows immediately something about that organism. For example: One hears mentioned an organism der Sperling, but does know what this organism is. But if one is also told that der Sperling is a bird, then one knows at once that this organism has feathers and wings, can probably fly, and is warm-blooded. One knows also it has a fourchambered heart that differs from a mammal's, legs without feathers, some hollow bones, and a way of disposing of nitrogenous waste sometimes inconvenient to automobiles and passers-below. One knows all these things 
about der Sperling because one knows it is a bird, not because one knows that Sperling is the German word for "sparrow."

In the same way, if one knows that Reduviidae is a family in the insect order Hemiptera, then one knows that reduviids must have sucking mouthparts, and other hemipteran features. And, as members of the hemipteran suborder Heteroptera, reduviids must have forewings partly opaque and partly membranous, and other heteropteran features. Again, one knows these things without knowing anything about reduviids themselves, but only that they are members of larger groups-larger groups about which one does know something.

Or, to take a more relevant example: In a fascinating paper, Gaunt and Miles (2000) summarize the habitats of the triatomine genera Rhodnius and Triatoma: most species in the former genus live in or associated with palms, and most species of the latter genus in or associated with rocky habitats. Therefore, if one finds a specimen in a collection of Rhodnius or of Triatoma, one can predict with some assurance where that specimen lived.

To put this more generally (although more confusingly), knowing to which group another group belongs, helps one to predict features or characteristics of that first group. This ability to predict of course depends upon the fact that all members (or most members) of a larger group share the features of that larger group. We know this in general because of common logic; and as biologists we know that this is how evolution, and especially speciation, occur. Differences accumulate in populations of the same species; these populations may become separate new species; over time some species become different enough to be genera, and genera become families, and so on. But each group-however different from the others-keeps the basic features of the group to which it belongs, and of the higher group to which that group belongs. And that is why knowing the group to which an organism belongs, allows us to predict many of that organism's characteristics.

But this does not explain completely why it is important to know an organism's direct relatives. If we know what family a subfamily belongs to we can make predictions about that subfamily. But what predictions can we make if we know that one subfamily is related to another? Here we no longer consider groups to which subgroups belong. Here we consider subgroups that belong to the same higher group-subgroups at the same hierarchical level. 
Two subgroups in the same group (for example, two subfamilies in the same family) may be more closely related to each other than either is to a third subgroup. For example, a brother and a sister are more closely related to each other than either one is to a cousin; geneologically, a brother and his sister and his cousin are all of the same generation, and therefore all at the same hierarchical level. The brother and sister have the same parents; but they and their cousin have the same grandparents-an entire generation's distance from their parents. Brother and sister are geneticallyand therefore phylogenetically-closer than either is to a cousin.

In terms of cladistics, brother and sister are sister-groups, whereas brother plus sister, together, is a sister-group to their cousin. Brother and sister are more alike-genetically closer-than either is to their cousin. And so if we know something about the brother, we can guess-or predictsomething about the sister (and vice versa). If we know some things about the cousin, we can guess-predict-some things about the brother and the sister-but not so many things, and not so accurately.

The situation is exactly the same with subfamilies in a family: more specifically, with subfamilies in the family Reduviidae. And even more specifically, with the reduviid subfamily Triatominae and other reduviid subfamilies. If we know the cladistic sister-group of Triatominae (its "brother" or "sister," so to speak), we can perhaps make some predictions about Triatominae, based on what we know about that sistergroup subfamily.

This means there now could be two ways to learn about Triatominae. First, of course, is to study them. But second, is to study their relatives, and apply what we learn to Triatominae. Each of these two ways to learn about triatomines can be used to check or verify the other: If we learn something by observation of one species of Triatominae, and we find the same thing in a closely related subfamily, then we have some confidence that what we found in that single triatomine species occurs also in other triatomine species. By studying both triatomines and their relatives, we can build up a body of knowledge with some hope that it is true of all, or most, triatomines. This kind of knowledge is very useful, of course, for understanding these bugs, and therefore for controlling them.

But the key here is: What other reduviid groups are the most closely related to Triatominae? There are two obstacles to answering this question.

The first obstacle is a common one: We simply do not know which of the other reduviid subfamilies is sister-group of the Triatominae. 
This problem occurs in most other groups of organisms too-only a tiny number of groups of organisms has been analyzed cladistically.

The second obstacle is more interesting: The possibility that the reduviid subfamily Triatominae is not a valid subfamily at all-that is, that Triatominae is made up of several groups of genera which are in fact not related to one another. I shall come back to this possibility.

Working out the relationships between Triatominae and other reduviid subfamilies is difficult. As a result, each of the few cladistic analyses of these subfamilies presents a different subfamily as the sister-group of Triatominae.

There are in fact remarkably few studies of the reduviid subfamilies. In a Biosis search (August, 2004), using Reduviidae and phylogeny, I got only 14 hits, from 1987 through 2003. Of these 14 hits, 8 were papers on phylogeny of genera or species within Triatominae; 3 were papers on Heteroptera or Insecta which mentioned Reduviidae (including one of mine!); 3 more dealt with phylogeny of genera or species in nontriatomine subfamilies; and none at all considered relationships of the reduviid subfamilies.

However, one study not found in Biosis has been published: In it, Ambrose (1999) suggests the Ectrichodiinae and Triatominae both evolved from Salyavatinae, whose members evolved the tibiarolium (see below) and several other features. This work is based to a considerable extent on Indian species.

In addition, there are at least two unpublished cladistic studies of reduviid subfamilies, one of them as yet incomplete. In a cladistic analysis for her Doctoral dissertation, Dr. Rebecca Clayton (1990) analyzed the reduviid subfamilies cladistically; and Dr. Maria Coscarón, of the La Plata Museum, is working now on a cladistic analysis of the subfamilies. In four of Clayton's (1990) six equally parsimonious trees, Stenopodainae was the sister group of Triatominae, and in the remaining two trees the sister group was a polytomy of most nontriatomine subfamilies. Coscarón's very preliminary results (in preparation) suggest Peiratinae+Vescinae may be the sister group of Triatominae.

In his account of reduviid groups allied with the subfamily Harpactocorinae, Davis (1969) did not consider Triatominae; but his Table 1 shows that Triatominae shares one advanced character (apomorphy) with all members of the harpactocoroid complex, and also with the subfamilies Peiratinae and Physoderinae. The latter is interesting, for two 
reasons: First, Lent and Wygodzinsky (1989) suggest a possible sister group relationship between Physoderinae and Triatominae; and second, because it has been pointed out that at least one physoderine-one of only two neotropical members of the subfamily so far known-may also feed on vertebrate blood (Cryptophysoderes fairchildiWygodzinsky \& Maldonado Capriles: Carcavallo \& Tonn, 1976). The other neotropical physoderine (Harpinoderes cicheroi Martinez \& Carcavallo) is predaceous on insects (Martinez and Carcavallo 1989). A further (but slight) connection between New World Physoderinae and Triatominae is that in both Harpinoderes and Cryptophysoderes, the rostral formula is 2>1>3 (Wygodzinsky \& Maldonado, 1972, Fig. 3C; Martinez \& Carcavallo, 1989, Fig. 3B), which is probably the plesiomorphic condition in Triatominae (Schaefer, unpublished).

A possible connection between Triatominae and Harpactocorinae is only slightly supported by Davis's work. At first appearing to lend additional support is the similarity between the triatomine genus Torrealbaia and the Harpactocorinae. Torrealbaia was described by Carcavallo et al. (1998) in the Triatominae because of its overall similarity to the triatomine Cavernicola. They noted that Torrealbaia also bears some resemblance to the harpactocorine, Amphibolus, but has a distribution incompatible with that of Amphibolus. Recently, Forrero et al. (2004) have shown that Torrealbaia is in fact a true harpactocorine, and indeed a member of the genus Amphibolus. It becomes more difficult, therefore, to use this relationship between Torrealbaia and Harpactocorinae as evidence of a triatomineharpactocorine relationship, especially as the Torrealbaia-Triatominae similarities are superficial.

Another problem is that a characteristic of one group may occur sporadically in scattered members of other groups. The lack in Triatominae of dorsal abdominal scent gland openings is (as I have mentioned) unusual in Heteroptera, and a characteristic of Triatominae. However, these openings are lacking also in a scattering of members of several other reduviid subfamilies (Lent \& Wygodzinsky, 1989).

Establishing the subfamily relationships of Triatominae is therefore difficult, as the great amount of disagreement among these results proves. The difficulty lies mostly in the fact there has been too little intense and detailed work on these relationships. However, there are other problems. Some of these problems are ones of method.

First, many of the character states used in these cladistic analyses occur in some but not in all of the subfamilies analyzed. In addition, these 
subfamily analyses never survey all genera in each subfamily (impossible: there are nearly 1000 genera in the family Reduviidae [Maldonado, 1990]). As a result, a character state may be coded one way or another depending upon which representative(s) of the subfamily are (is) studied. Quite possibly, one character state exists in the representative of a subfamily studied by one worker, whereas another state of the same character exists in a different representative of the same subfamily studied by another worker. And so, sampling of genera can determine the resulting cladogram, and thus can determine the cladistic relationships between one reduviid subfamily and another. And if different and representatives of the same groups differ, the resulting cladistic analyses may differ also.

Here are a few examples of the difficulty caused by this sort of sampling problem. Recently, Weirauch (2003) surveyed the cave organ in 21 subfamilies of Reduviidae, building on earlier work by Catalá and colleagues (1998). The cave organ is a sensory structure (probably chemosensory) found in the basal segment of the antenna (the pedicel). Of the 21 reduviid subfamilies surveyed, the cave organ is found in only four-Peiratinae, Reduviinae, Stenopodainae, and Triatominae. One might conclude that possession of this structure, the cave organ, is a synapomorphy of these four subfamilies, and indicates that they are closely related. May be so. But, the cave organ is absent from some members of every one of these 4 subfamilies. And we have no idea whether the cave organ is present in those genera that were not sampled at all. In fact, we do not even really know if the cave organ is absent from those 17 subfamilies in which Weirauch did not find it-because here too she did not look at every genus and, of course, could not. So this character, which at first seemed so useful, we now see is ambiguous, because of the difficulty of complete and adequate sampling.

Moreover, it has been suggested (but only suggested) that some triatomine genera are most closely related not to other triatomine genera but to Reduviinae. But it is not certain that the subfamily Reduviinae itself is monophyletic-the members of this subfamily lack good synapomorphies (Weirauch, 2003). This uncertainty makes more difficult the argument that some triatomines are really reduviines-more difficult because we cannot really say what a reduviine is!

Confusion heaped upon confusion.

Weirauch (2003) also showed that these 4 subfamilies-Peiratinae, Reduviinae, Stenopodainae, and Triatominae-all have a group of long 
sensory hairs (trichobothria) on the antenna's pedicel. This is an apomorphic character, but it also occurs in nearly two-thirds of the remaining reduviid subfamilies; and so this character is not very useful in suggesting relatives of the Triatominae. And, of course, the same problems with sampling remain, as before.

Another character that presents the same kind of problem is the presence of a spongy furrow (fossula spongiosa, or tibiarolium) on the fore and hind tibiae. This occurs in 5 reduviid subfamilies, including Triatominae (Murugan \& Livingstone 1995). However, of the 4 other subfamilies, only 2-Reduviinae and Peiratinae-also share with Triatominae the cave organ of the antenna (Weirauch, 2003).

Possession of both the cave organ and the tibiarolium tends to support the idea that these 3 subfamilies are related - that is, Peiratinae, Reduviinae, and Triatominae. But again, sampling among the reduviid subfamilies for the tibiarolium is as poor as is the sampling for the cave organ. And, also again, the subfamily Reduviinae may not be monophyletic.

The eggs of Triatominae and Ectrichodiinae are of a similar simplicity (Southwood, 1956; Haridass, 1986), which might suggest an evolutionary relationships; but George (1988) notes similarities between the eggs of Triatoma rubrofasciata and a salyavatine, Platymeris laevicollis Distant. In each case, of course, the number of genera sampled was very low and, of course, one must not be seduced by similarity into phylogenetic speculation.

I do not mean to suggest that this problem of sampling is unique to the subfamilies of Reduviidae: far from it. The problem occurs in the systematic analyses of all groups, because it is simply impossible to examine and record the characters from all subgroups during the analysis of a group. The problem is particularly troublesome in Insecta, because here the groups are so large, and therefore the sample sizes must be relatively so small.

My point here is that the subfamily Triatominae, or some of its members, shares various character states with various other reduviid subfamilies, or some of their members. This fact does not mean that Triatominae, or any of its members, are phylogenetically related to these other reduviids. This fact does mean that all these bits of evidence must be analyzed and evaluated, and the effects of sampling taken into consideration. It may mean that different subgroups within Triatominae are related to different reduviid subfamilies-that is, it may mean that Triatominae is indeed di- or polyphyletic. But, so far, all these bits of evidence 
point in so many directions at once that, in fact, they point in none and, so far, prove nothing.

Confusion heaped upon confusion heaped upon confusion.

Blood-feeding has been considered a unique evolutionary feature of Triatominae. And here sampling is good-blood-feeding occurs throughout the subfamily. Because all triatomines possess this feature, and because this is an advanced feature unusual in Hemiptera and in Reduviidae itself, many people believe it shows that Triatominae is a single evolutionary unit that has evolved only once-therefore, that Triatominae is monophyletic.

However, it has been asserted (although by no means proven or even discussed in detail) that feeding on vertebrate blood has evolved several times in the evolution of Reduviidae. The suggestion is based on the idea that the morphological features that hold the subfamily together as a subfamily, are all associated with blood-feeding. Therefore, the suggestion continues, if various members of different reduviid subfamilies all independently come to feed on vertebrate blood, then all these unrelated blood-feeding reduviids would have the same morphological adaptations for blood-feeding. And therefore all would look the same and all would be grouped together. Therefore, the subfamily Triatominae is not made up of closely related genera, and is therefore not monophyletic.

This idea has been presented in several places by several people [see Schaefer (2003), and discussion therein]. But, so far, there is no evidence to support it. Moreover, at least two features unique to Triatominae seem not to be adaptations for blood-feeding. Triatomines lack dorsal abdominal scent glands (which occur throughout the Heteroptera); and the rostrum, or beak, is straight and its third segment flexes upward during feeding. It is not clear how these features are specifically adapted for bloodfeeding.

In addition, Schaefer and Coscarón (2001) assembled about 20 characters also not obviously associated with blood-feeding and which occur in all or most triatomines. A similarity analysis strongly suggests that all triatomine genera are indeed related. A cladistic analysis, using the same characters and several other reduviid subfamilies as outgroups, is underway.

I mentioned above the importance-the medical importance-of knowing to what other reduviid groups the Triatominae are related. It is equally important to determine if in fact different triatomine genera are related most closely to other reduviid subfamilies. 
It is particularly important to know the same about the genus Linshcosteus. This is the only genus all of whose species occur in the Old World (specifically, in India); Rajan \& Ambrose (1995) describe the bloodfeeding of L. kali Lent \& Wygodzinsky. Several Triatoma species also occur only in the Old World, and Triatoma rubrofasciata (De Geer) occurs in both the New and the Old Worlds. But Linshcosteus alone is exclusively an Old World genus, a fact which makes Linshcosteus of great evolutionary interest. But the fact has important medical consequences as well.

As I have argued elsewhere (Schaefer, 1998), if Linshcosteus is a triatomine, it may have the potential of being a vector of some trypanosome similar to that which causes Chagas disease. Although Trypanosoma cruzi does not occur in the Old World (as far as we know), relatives of Trypanosoma cruzi do (Weinmann et al., 1978; Schofield, 2000), and have been found in at least one species of Linshcosteus (Patterson et al., 2001). If Linshcosteus is actually and phylogenetically a triatomine, it could be of medical importance, because it could harbor other and perhaps harmful Trypanosoma species, or even Trypanosoma cruzi, if that protozoan should reach India (or be there already). [If, as seems likely Stevens et al., (1999), T. cruzi arose in Gondwana, it is at least possible that it, or a close relative, occurs as yet undiscovered in India.]

However, if Linshcosteus is not a triatomine, and is therefore not related to other triatomines, or is not related to bugs that transmit Trypanosoma cruzi-If Linshcosteus is a phylogenetically separate genus, then it is less likely to be of medical significance. If Linshcosteus has acquired its blood-feeding habit independently, then it is not likely to become a vector of medically important trypanosomes. Therefore, for medical reasons, it is important to discover what the phylogenetic relatives of Linshcosteus are.

This brings us back to the same problem, but at the level of genus, not subfamily: What are the genera most closely related to Linshcosteus, and are these genera true triatomines?

I strongly suggested above that we can learn about the subfamily Triatominae by knowing its phylogenetic relationships. Now I suggest exactly the same thing about the genera of Triatominae. If we know the relationships of these genera, we can learn more about their biology, behavior, and so on. But learning these relationships is complicated by the possibility that these genera may actually not be related closely to each other; the complication that several of these triatomine genera, or groups of genera, may actually be more closely to other reduviids that do not belong in 
Triatominae, and less closely related to genera that do belong in Triatominae. This is the complication caused by the fact that the subfamily Triatominae may not be monophyletic-the same problem I outlined earlier (above, and in Schaefer, 2003).

The question of the monophyly or polyphyly of Reduviidae must be clearly stated, worked out, and answered (so far, none of these three necessities has been addressed in sufficient detail). The question must be worked out for several reasons, but most importantly because of the medical importance of the triatomine genera. And especially because of the possibility of the medical importance in India of Linshcosteus.

Therefore there are two problems: First, to what other subfamily of Reduviidae is the subfamily Triatominae most closely related? And second, Are the genera within Triatominae more closely related to one another than either, or several, are related to genera not within Triatominae? The second question can be more easily phrased this way: Is Triatominae monophyletic, diphyletic, polyphyletic?

It appears that it is necessary to answer the second question before trying to answer the first one. However, answering the first one might help answer the second-because proving that every genus now in Triatominae is closely related to a single other subfamily, would help prove that Triatominae is in fact monophyletic. But all triatomine genera would have to be included in this analysis.

And so we need much more work concentrated on the evolutionary relationships of the genera now included in Triatominae, and on the evolutionary relationships of the subfamilies in Reduviidae. There has been much speculation on these relationships, but not much actual study (Schaefer, 2003)

We need these studies for the reasons above, and for one more. The reasons already stated are these: Many members of the Triatominae are vectors of Trypanosoma cruzi, which causes a serious and often fatal disease, Chagas disease; moreover, the blood loss itself, of these bugs' feeding, can be dangerous to the weak, the old, and the newborn. To help control these bugs we need to know more about them—about their ecology, biology, physiology, behavior, and so on. We can learn more about them by extrapolating to them what we know already about their evolutionary, that is their phylogenetic, relatives. But to do this, we must know exactly what those relatives are. Discovering what those relatives are, is difficult, but not impossible. 
But there is another reason for studying the evolutionary relationships of Triatominae, a reason I have not mentioned. It is this: To know these things is to know more about the natural world, and to satisfy a basic urge of humans-curiosity. And that, by itself, is good. As the English poet A. E. Housman wrote more than a century ago, "Let a man acquire knowledge... not because it is useful or ornamental... but because it is knowledge and therefore good for a man to acquire" (Housman, 1892; published 1937).

Addendum: Since this paper was written, another on triatomine relationships has appeared. In this important paper, Paula et al. (2005) analyze mitochondrial rDNA sequences of several triatomine genera and species, as well as some representatives of other reduviid subfamilies. The analysis shows a close sister-group relationship between Linshcosteus sp. and Triatoma. More importantly, it also indicates both that the Triatominae itself and both Rhodnius and Triatoma are polyphyletic. This is so far the best evidence that these groups are indeed polyphyletic, and that Triatominae either is not a phylogenetically valid subfamily, or that only part of it (some genera, and perhaps some species of other genera) compose a valid subfamily. However, some doubt may be cast on these conclusions by the fact that whenever in the analysis there is more than one nontriatomine species of the same genus, those species are separated cladistically; thus the same evidence that suggests Triatominae is polyphyletic, also suggests that Harpactocorinae and Reduviinae are polyphyletic (or diphyletic) also. Clearly, this paper (Paula et al., 2005) is a significantly valuable contribution. But also clearly, it must be supported by additional analyses of additional characters (including morphological characters).

\section{Acknowledgments}

I am deeply grateful to José Jurberg for inviting me to the Roundtable (XX Congresso Brasileiro de Entomologia. Gramado, RGS) at which this was presented, and for then inviting me to prepare it for this journal. I am grateful also to Cleber Galvão and Antônio Panizzi for their encouragement as I prepared this paper, and to Alexandre Silva de Paula for sending me an advance copy of his paper and for discussions about it. I also thank Maria Coscarón, with whom I have worked on triatomine relationships and who permitted me to see her work-in-progress on reduviid relationships. 


\section{References}

Ambrose, D.P., 1999. Assassin Bugs. Science Publishers, Enfield, New Hampshire, U.S.A. 337 p.

Carcavallo, R.U.; Jurberg, J. \& Lent, H., 1998. Torrealbaia martinezi, gen. nov., sp. n., da tribo Cavernicolini (Hemiptera, Reduviidae, Triatominae): Uma abordagem filogenética. Entomol. Vect. 5: 143-150.

Carcavallo, R.U.; Jurberg, J.; Lent, H.; Noireau, F. \& Galvão, C., 2000. Phylogeny of the Triatominae (Hemiptera: Reduviidae). Proposals for taxonomic arrangements. Entomol. Vect. 7 (Supl. 1):1-99.

Carcavallo, R.U. \& Tonn, R.J., 1976. Clave gráfica de Reduviidae (Hemiptera) hematófagos de Venezuela. Bol. Dir. Malariol. Saneamiento Amb. 16:244-264.

Catalá, S.; Tomasi, V.; Hliba, E. \& Rovaso, R., 1998. The cave organ in Triatominae (Hemiptera, Reduviidae) antennae: an olfactory receptor? Biocell 22:1-7.

Forero, D.; Weirauch, C. \& Baena, M., 2004. Synonymy of the reduviid (Hemiptera: Heteroptera) genus Torrealbaia (Triatominae) with Amphibolus (Harpactocorinae), with notes on Amphibolus venator (Klug, 1830). Zootaxa 670:1-12.

Galvão, C.; Carcavallo, R.; Rocha, D.S. \& Jurberg, J., 2003. A checklist of the current valid species of the subfamily Triatominae Jeannel, 1919 (Hemiptera, Reduviidae) and their geographical distribution, with nomenclatural and taxonomic notes. Zootaxa 202:1-36.

Gaunt, M. \& Miles, M., 2000. The ecotypes and evolution of triatomine bugs

(Triatominae) and their associated trypanosomes. Mem. Inst. Oswaldo Cruz 95:557-565.

George, A.R., 1988. Biology of the eggs of the assassin bugs (Heteroptera: Reduviidae) of western ghats, India. PhD dissertation, Bharathiar Univ., Coimbatore, India, 202 p. 
Haridass, E.T., 1986. Ultrastructure of eggs of Reduviidae: III. Eggs of Triatominae and Echtrichodiinae [sic] (Insecta-Heteroptera). Proc. Indian Acad. Sci. 95:447-456.

Henry, T.J., 1997. Phylogenetic analysis of family groups within the infraorder Pentatomomorpha (Hemiptera: Heteroptera), with emphasis on the Lygaeoidea. Ann. Entomol. Soc. Am. 90:275-301.

Housman, A.E., 1937. Introductory Lecture, Delivered Before the Faculties of Arts and Laws and of Science in University College, London, October 3, 1892. The Macmillan Company, New York, New York. $36 \mathrm{p}$.

Maldonado Capriles, J., 1990. Systematic Catalogue of the Reduviidae of the World. Puerto Rico, U.S.A., Special Publication, Caribb. J. Sci. $694 \mathrm{p}$.

Martinez, A. \& Carcavallo, R.U., 1989. Physoderinae neotropicales (Hemiptera-Reduviidae). Chagas 5:11-18.

Murugan, C. \& Livingstone, D., 1995. Keys to the south Indian species of tibiaroliate assassin bugs (Heteroptera: Reduviidae). J. Entomol. Res. 19:265-275.

Patterson, J.S.; Rajen, K.; Ambrose, D.P. \& Miles, M.A., 2001. First record of trypanosomesfrom the endemic Indian genus of Triatominae, Linshcosteus sp. nov. [L. karupus Galvão et al.]. Trans. R. Soc. Trop. Med. Hyg. 95:248-249.

Paula, A.S., L. Diotaiuti, and C.J. Schofield 2005 (in press), Testing sistergroup relationship of the Rhodniini and Tritomini (Insecta: Hemiptera: Reduviidae: Triatominae). Molec. Phylog. Evol. (in press).

Rajan, K. \& Ambrose, D.P. 1995. Feeding behaviour of Linshcosteus kali Lent and Wygodzinsky, a haematophagous triatomine assassin bug. Insect Environment 1:15-16. 
Schaefer, C.W., 1995. Review of Schofield 1994. J. Med. Entomol. 32:911912.

Schaefer, C.W., 1998. Phylogeny, systematics, and practical entomology: the Heteroptera (Hemiptera). An. Soc. Entomol. Bras. 27:499-511.

Schaefer, C.W., 2000. Adventitious biters-"nuisance" bugs. p. 553-559 In: Heteroptera of Economic Importance (C.W. Schaefer and A.R. Panizzi, eds). CRC Press, Boca Raton, Florida, U.S.A. 828 p.

Schaefer, C.W., 2003. Triatominae (Hemiptera: Reduviidae): systematic questions and some others. Neotrop. Entomol. 32:1-10.

Schaefer, C.W., 2003 (publ. 2004). Heteropteran adventitious biters (Hemiptera): primitively predaceous? Entomol. News 114:211-216.

Schaefer, C.W. \& Coscarón, M.C., 2001. The status of Linshcosteus in the Triatominae (Hemiptera: Reduviidae). J. Med. Entomol. 38:862-867.

Schofield, C.J., 1994. Triatominae Biology \& Control. Eurocommunica Publications, West Sussex, England. 77 p.

Schofield, C.J., 2000. Trypanosoma cruzi-the vector-parasite paradox. Mem. Inst. Oswaldo Cruz 95:535-544.

Southwood, T.R.E., 1956. The structure of the eggs of terrestrial Heteroptera and its relationships to the classification of the group. Trans. R. Entomol. Soc. London 198:163-221.

Stevens, J.R.; Noyes, H.A.; Dover, G. A. \& Gibbons, W.C., 1999. The ancient and divergent origins of the human pathogenic trypanosomes, Trypanosoma brucei and T. cruzi. Parasitology 118:107-116.

Weinmann, D.; Wallis, R.C.; Cheong, W.H. \& Mahadevan, S., 1978. Triatomines as experimental Vectors of trypanosomes of Asian monkeys. Am. J. Trop. Med. Hig. 27:232-237. 
Weirauch, C., 2003. Pedicellar structures in Reduviidae (Heteroptera)comments on cave organ and trichobothria. Europ. J. Entomol. 100:571-580.

Wygodzinsly, P. \& Maldonado Capriles, J., 1972. Description of the first genus of Physoderine assassin bugs (Reduviidae, Hemiptera) from the New World. Am. Mus. Novit. 2504:1-5. 